\title{
GCU
}

Glasgow Caledonian

University

University for the Common Good

\section{Use of lanthanide-containing polyoxometalates to sensitise the emission of fluorescent labelled serum albumin}

Holmes-Smith, A. Sheila; Crisp, Jacob; Hussain, Firasat; Patzke, Greta R.; Hungerford, Graham

Published in:

ChemPhysChem : a European Journal of Chemical Physics and Physical Chemistry

DOI:

$10.1002 /$ cphc. 201500954

Publication date:

2016

Document Version

Author accepted manuscript

Link to publication in ResearchOnline

Citation for published version (Harvard):

Holmes-Smith, AS, Crisp, J, Hussain, F, Patzke, GR \& Hungerford, G 2016, 'Use of lanthanide-containing polyoxometalates to sensitise the emission of fluorescent labelled serum albumin', ChemPhysChem : a European Journal of Chemical Physics and Physical Chemistry, vol. 17, no. 3, pp. 418-424. https://doi.org/10.1002/cphc.201500954

\section{General rights}

Copyright and moral rights for the publications made accessible in the public portal are retained by the authors and/or other copyright owners and it is a condition of accessing publications that users recognise and abide by the legal requirements associated with these rights.

Take down policy

If you believe that this document breaches copyright please view our takedown policy at https://edshare.gcu.ac.uk/id/eprint/5179 for details of how to contact us. 


\title{
Use of lanthanide containing polyoxometalates to sensitise the emission of fluorescent
} labelled serum albumin

\author{
A. Sheila Holmes-Smith ${ }^{[a]}$, Jacob Crisp ${ }^{[a]}$, Firasat Hussain ${ }^{[b]}$, Greta R. Patzke ${ }^{[c]}$ and Graham \\ Hungerford ${ }^{*[d]}$
}

\begin{abstract}
Monitoring the interaction of biomolecules is important and the use of energy transfer is a principal technique in elucidating nanoscale interactions. Lanthanide compounds are promising luminescent probes for biological samples as their emission is longer-lived than any native autofluorescence. Polyoxometalates (POMs) are interesting structural motifs to incorporate lanthanides, offering low toxicity and a size pertinent for biological applications. Here we employ iso-structured POMs containing either terbium or europium and assess their interaction with serum albumin by sensitisation of a fluorescent tag on the protein via LRET (luminescence resonance energy transfer) by exciting the lanthanide. Time-resolved measurements showed energy transfer with an efficiency of over $90 \%$ for the POM-protein systems. The Tb-POM results were relatively straightforward, while those with the isostructured Eu-POM were complicated by the effect of protein shielding from the aqueous environment.
\end{abstract}

\section{Introduction}

The polyoxometalate (POM) structural motif is an interesting one for the incorporation of lanthanide ions ${ }^{[\overline{1}]}$. Although not strictly a nanomaterial, POMs exhibit many properties useful in the biological and medicinal fields; they are small $(<5 \mathrm{~nm})$ and stable in biological media. These structures are generally considered to be of low toxicity and environmentally benign. ${ }^{[\overline{2}]}$ This means that there is potential for their use in theranostics and POMs have been applied in anti-cancer, ${ }^{[3,4]}$ prions ${ }^{\left[{ }^{[5]}\right]}$ and anti-viral ${ }^{\left[{ }^{[6]}\right.}$ studies. Recently they have also been employed for photosensitisation and catalysis. ${ }^{[7-9]}$ The fact that POMs can include lanthanide $\left(\mathrm{Ln}^{3+}\right)$ ions enables their luminescence properties to be utilised. There is an existing interest in using lanthanide ions as optical

\footnotetext{
[a] Dr. A.S. Holmes-Smith, J. Crisp

School of Engineering and Built Environment

Glasgow Caledonian University

Cowcaddens Road, Glasgow G4 OBA, UK

[b] Dr. F. Hussain

Department of Chemistry

University of Delhi

Delhi -110007, India

[c] Prof. Dr. G.R. Patzke

Department of Chemistry

University of Zurich

Winterthurerstrasse 190, CH-8057 Zurich, Switzerland

[d] Dr. G. Hungerford

HORIBA Jobin Yvon IBH Ltd

133 Finnieston Street, Glasgow G3 8HB, UK

Email: graham.hungerford@horiba.com
}

biological probes and this stems from their emission, which spans wavelengths from the ultraviolet to the near infrared Generally this emission, which emanates from transitions in the $4 f$ shell, is "line-like" in nature ${ }^{[10-12]}$. Also lanthanide luminescence is on a longer timescale ( $\mu \mathrm{s} / \mathrm{ms}$ ) than that associated with fluorescence (ps / ns), which enables differentiation from background fluorescence. This is advantageous in bioanalytical applications ${ }^{[13,14]}$, as is their stability in relation to photobleaching. ${ }^{[13]}$ These factors are promising for application in the area of bioimaging, ${ }^{[15-18]}$ although their usage can be affected by the fact that simple lanthanides can possess low extinction coefficients. This has lead to the use of antenna and other structures to enable efficient excitation ${ }^{[10,13,19]}$ and complexes have been developed with high quantum yields for use as biological stains. ${ }^{[20]}$ Two ions that are frequently employed in biomolecular systems because of their luminescent properties are $\mathrm{Tb}^{3+}$ and $\mathrm{Eu}^{3+}{ }^{[21]}$ It should be noted that the ${ }^{5} D_{0} \rightarrow{ }^{7} F_{2}(\sim 613 \mathrm{~nm})$ transition in $\mathrm{Eu}^{3+}$ is sensitive to its co-ordination environment, whereas $\mathrm{Tb}^{3+}$ exhibits transitions that are not as sensitive to environmental influence. Even when incorporated into POMs the solvent can have an influence ${ }^{[22]}$ and we have seen that $\mathrm{Eu}^{3+}$ emission can be affected by its microenvironment. ${ }^{[23]}$ POMs have been shown to interact with proteins, such as human serum albumin $(\mathrm{HSA})^{[24-28]}$ and we have reported the influence of serum albumin on the emission of $\mathrm{Eu}^{3+}$ and $\mathrm{Tb}^{3+}$ containing POMs. ${ }^{[29]}$.

A common technique to elucidate interactions between biomolecules is to monitor energy transfer between a donor and acceptor moiety via the Förster mechanism (FRET). ${ }^{[30]}$ Earlier works, notably by Selvin have employed the lanthanide, with its longer-lived emission, as the donor, while making use of a fluorescent molecule as the acceptor. ${ }^{[31-34]}$ This approach has been employed in assays ${ }^{[35-37]}$ and contrasts with the more usual approach of engineering an antenna complex which can transfer energy to the lanthanide. ${ }^{[18]}$ By sensitising the emission of a fluorescent acceptor luminescence resonance energy transfer $(\mathrm{LRET})^{[31]}$ leads to emission from the acceptor which is longerlived than its native fluorescence lifetime. The acceptor lifetime then reflects that of the quenched donor. When using LRET it can be easier to distinguish the acceptor emission from any background fluorescence, which can be substantial in both in vivo and in vitro cell studies. The usual rules for FRET apply to

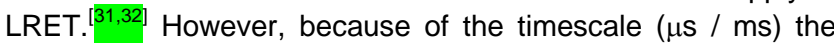
acceptor molecule should be in a random orientation (because of rotational motion), thus the error in estimating the orientation factor $\left(\kappa^{2}\right)$ is reduced. This can be problematic using fluorescence and therefore LRET can allow a better determination of intermolecular distances. ${ }^{[32]}$ Also the Förster distance (distance at which energy transfer is 50\% efficient) can be longer in LRET in comparison to FRET. ${ }^{[21]}$ There have been reports employing lanthanide emission in the visible 
spectral region, using $\mathrm{Tb}^{3+}$ to sensitise the emission of fluorescein ${ }^{[33]}$ or rhodamine ${ }^{[38]}$ and $\mathrm{Eu}^{3+}$ to sensitise sulforhodamine-101 ${ }^{[39]}$ and $\mathrm{CY}-5^{[34]}$. However, there has been little (if any) work performed in using lanthanide containing POMs to sensitise the emission from a fluorescent labelled protein

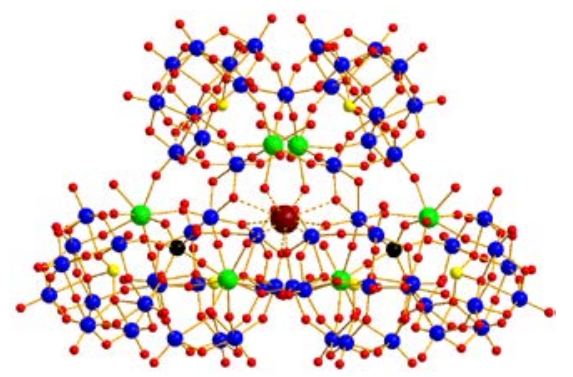

$\mathrm{Na}_{22} \mathrm{Cs}_{3}\left[\mathrm{Cs} \subset \mathrm{Eu}_{6} \mathrm{As}_{6} \mathrm{~W}_{63} \mathrm{O}_{218}\left(\mathrm{H}_{2} \mathrm{O}\right)_{14}(\mathrm{OH})_{4}\right] \cdot \mathrm{CsCl} \bullet 76 \mathrm{H}_{2} \mathrm{O}$ (Eu-POM) $\mathrm{Na}_{21} \mathrm{Cs}_{4}\left[\mathrm{Cs} \subset \mathrm{Tb}_{6} \mathrm{As}_{6} \mathrm{~W}_{63} \mathrm{O}_{218}\left(\mathrm{H}_{2} \mathrm{O}\right)_{14}(\mathrm{OH})_{4}\right] \bullet 76 \mathrm{H}_{2} \mathrm{O} \quad$ (Tb-POM)

Scheme 1. POM structures used in this study

In this work we employ two iso-structured POMs, incorporating either $\mathrm{Eu}^{3+}$ or $\mathrm{Tb}^{3+}$, see Scheme 1. These have been established to interact with serum albumin. ${ }^{[29]}$ Although these structures are relatively large in comparison to an organic dye and they contain several lanthanide ions, the timescale of their emission (micro- $/$ millisecond) means that the individual ions appear to contribute to a common photophysical behaviour for each POM. This can be seen by the fact that the decay for the $\mathrm{Tb}^{3+}$ containing POM can be modelled by a single exponential decay. ${ }^{[29]}$ This means that, for this work, we will consider the luminescence as arising from a single entity. To advance the usage of these compounds in a more applicable manner the study of energy transfer with the lanthanide acting as donor, sensitising the emission of a short-lived fluorophore as acceptor, requires exploration. Excitation of the lanthanide containing POMs was made at wavelengths that were accessible to commonly available pulsed semiconductor lasers (378 $\mathrm{nm}$ for $\mathrm{Tb}^{3+}$ and $392 \mathrm{~nm}$ for $\mathrm{Eu}^{3+}$ ). This would also allow future applications of their use in microscopy (bioimaging) or remote excitation via an optical fibre applications to be explored. We make use of the well known protein labels, fluorescein isothiocyaninate (FITC) and Texas Red (TR), attached to bovine serum albumin (protein used at relatively low concentrations $\sim \mu \mathrm{M}$ ) to act as acceptors for the $\mathrm{Tb}^{3+}$ and $\mathrm{Eu}^{3+}$ respectively. The choice of acceptor was made to give a suitable spectral overlap of the donor and acceptor emission (see experimental section) in order to facilitate energy transfer. Sensitisation was assessed using time-resolved luminescence, principally by recording the time-resolved emission spectra (TRES), which produces an intensitywavelength-time surface. Subsequent determination of the decay associated spectra enables a relationship between the spectra and their luminescence lifetimes to be made. These were calculated by plotting the pre-exponential factor for a particular lifetime (obtained from global analysis) against wavelength multiplied by that lifetime. This gives the amplitude of that lifetime contribution at a particular wavelength producing a spectrum associated with a lifetime.

\section{Results and Discussion}

\section{Tb-POM interaction with BSA-FITC}

The time-resolved measurements were performed on the TbPOM, both in absence and presence of FITC labelled BSA. The overall decays are shown in Figure 1 and it can clearly be seen that on addition of $\mu \mathrm{M}$ concentrations of FITC-BSA that the decay kinetic exhibits a significant amount of a shorter-lived component.

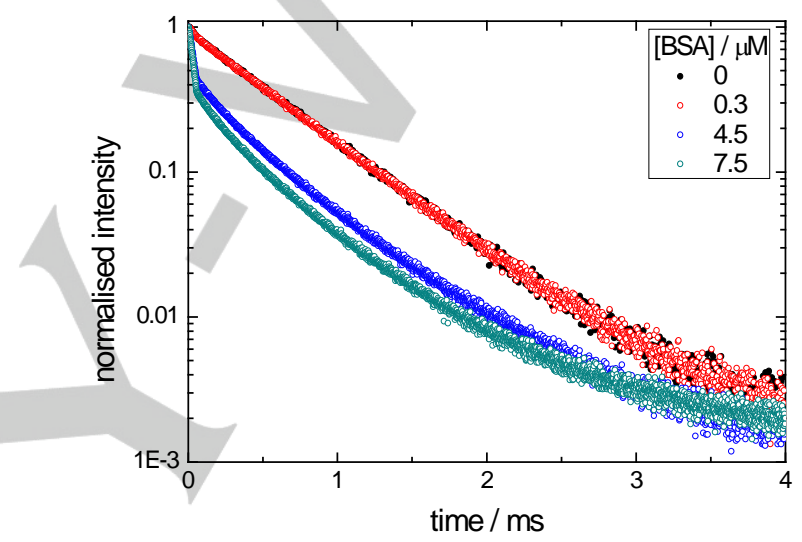

Figure 1. Normalised decays (obtained by summing all of the TRES decay curves) for the emission of the Tb-POM with different concentrations of the FITC labelled BSA.

On inspection of the decay associated spectra (Figure 2) the short-lived $(\sim 20 \mu \mathrm{s})$ spectrum increases with increasing FITCBSA concentration and exhibits the characteristic shape and peak wavelength of FITC fluorescence. ${ }^{[40]}$ The lifetime recovered is significantly longer than that for FITC bound to BSA ( $4 \mathrm{~ns})$ and therefore can be clearly ascribed to sensitised emission. The longer-lived $(-540 \mu \mathrm{s})$ clearly relates to $\mathrm{Tb}^{3+}$ emission. At the higher protein concentration there is also the presence of another component expressing the $\mathrm{Tb}^{3+}$ band shape. Both of these lifetimes are in keeping with those we have previously reported, with an increase in the $\sim 200 \mu$ s decay component associated with addition of protein to this POM. ${ }^{[29]}$ It is just possible to discern the presence of the sensitised emission from the FITC at the lower protein concentration $(0.3 \mu \mathrm{M})$, which becomes clearly visible when this is increased by a factor of ten.

From the lifetimes obtained it is possible (using equation (5) and taking $\tau_{\mathrm{d}}=540 \mu \mathrm{s}, \tau_{\mathrm{ad}}=20 \mu \mathrm{s}$ ) to calculate the efficiency of energy transfer for Tb-POM interacting with FITC-BSA of $\sim 96 \%$. It is apparent that on increasing the protein concentration, labelled BSA binds to more of the POM molecules leading to a higher proportion of the $\mathrm{Tb}^{3+}$ emission becoming quenched. This is observed in Figure 2 by the associated fractional of the $\sim 20 \mu \mathrm{s}$ 
lifetime increasing from $9 \%$ to $34 \%(0.3 \mu \mathrm{M}$ to $7.5 \mu \mathrm{M})$ of the overall emission. By monitoring changes in tryptophan emission in HSA upon addition of this POM we have suggested that there is a one to one binding process. ${ }^{[29]}$ Thus, as the POM is in excess the change in the pre-exponential is indicative of the proportion of the Tb-POM molecules interacting with protein. Here the labelling ratio (2.5) should be kept in mind, since unlabelled protein will also interact. As the shortest-lived decay value is constant this can be indicative of a fixed donor-acceptor distance. Using a reported value for $R_{0}$ ( $\mathrm{Tb}$ - fluorescein) of 45 $\AA^{[32]}$ would give a donor-acceptor separation of $26 \AA$ (using equation (6)). This is in keeping with values of $\sim 15$ to $27 \AA$ reported for different POMs interacting with human serum albumin (HSA), where energy transfer occurred from the trytophan in the HSA to the POM. ${ }^{\left[{ }^{26]}\right.}$ From the data that we obtained using the Tb-POM and labelled BSA it is possible to obtain information concerning both distance and extent of the POM - protein interaction.
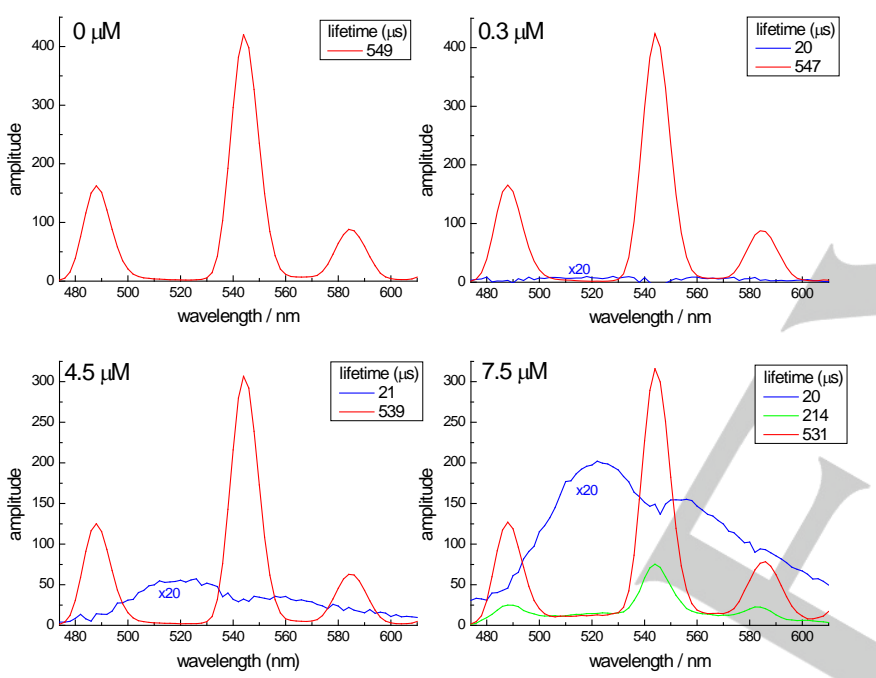

Figure 2. Decay associated spectra for the Tb-POM with different concentrations of FITC labelled BSA. The error on the lifetimes is $\sim 0.5 \mu \mathrm{s}$.

\section{Eu-POM interaction with TR-BSA}

As with the case of the interaction of the terbium containing POM with the FITC labelled BSA, a study was performed adding TR labelled protein to an aqueous POM solution. However, the results do not appear as straightforward as encountered using the FITC-BSA : Tb-POM system and are more indicative of the protein mediating the interaction of the environment. We have previously reported on the effect of protein interacting with this POM by monitoring the complete emission (by use of a long pass filter) and suggest the influence of the quenching effect of the $\mathrm{O}-\mathrm{H}$ oscillators on the $\mathrm{Eu}^{3+}$ emission becomes lessened upon interaction with the protein. ${ }^{[29]}$ In this work we make use of TRES measurements to enable wavelength differentiation. These were performed for each addition of the protein and the spectra obtained in a $2.6 \mu$ s period just after the "turn off" of the excitation laser are shown in Figure $3 a$. On this timescale, as well as a slight increase in the level of emission close to $600 \mathrm{~nm}$ (close to peak emission of Texas red), as labelled protein is added it is clear that there are spectral changes in the europium emission. For example the small band, appearing as a shoulder at $578 \mathrm{~nm}$ decreases and disappears. There also appears to be a $2 \mathrm{~nm}$ shift to shorter wavelengths in the $592 \mathrm{~nm}$ band and a corresponding $2 \mathrm{~nm}$ shift to longer wavelengths in the $614 \mathrm{~nm}$ band. A major feature is the ratio of the 592 to $614 \mathrm{~nm}$ (Figure $3 b)$ the ${ }^{5} \mathrm{D}_{0} \rightarrow{ }^{7} \mathrm{~F}_{1}$ transition $(\sim 590 \mathrm{~nm})$ in $\mathrm{Eu}^{3+}$ is magnetic in nature, while the transition ${ }^{5} D_{0} \rightarrow{ }^{7} F_{2}(-613 \mathrm{~nm})$ is electric and more environmentally sensitive. ${ }^{[11]}$ Concerning the longer wavelength emission at $700 \mathrm{~nm}\left({ }^{5} \mathrm{D}_{0} \rightarrow{ }^{7} \mathrm{~F}_{4}\right)$ a spectral change involving the growth of a band around $692 \mathrm{~nm}$ is observed. This band is also known to be environmentally sensitive hence the changes are consistent with those noted for the shorter wavelength transition. Overall the spectral changes are consistent with changes in the $\mathrm{Eu}^{3+}$ co-ordination sphere in the POM caused by the shielding effect of the protein from the aqueous environment. This is different behaviour to that observed in the Tb-POM system and although the structural similarity of both POMs should imply that they should interact in the same manner with the protein, it is clear that their spectral behaviour is different. These are factors that should be kept in mind if these compounds are to be employed in imaging or assay applications.
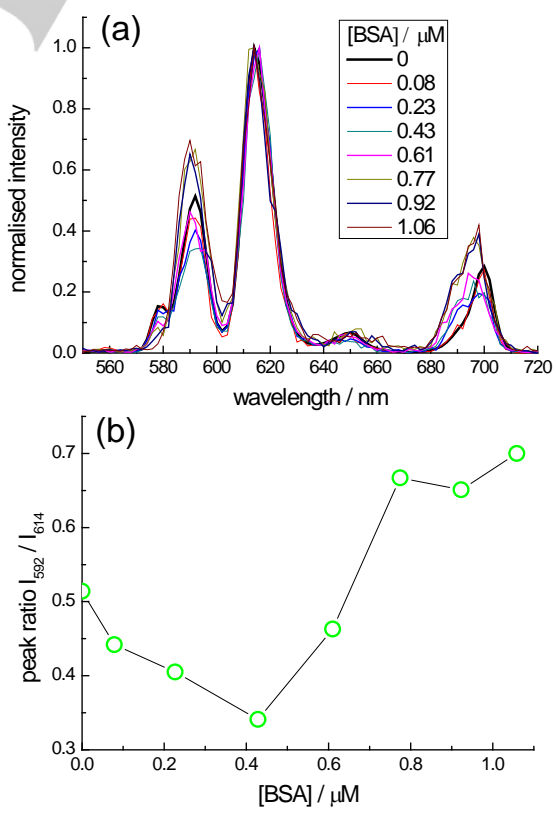

Figure 3. (a) Normalised TRES for Eu-POM obtained in the first $2.6 \mu$ s after turn off on the excitation source with addition of TRBSA. (b) change in the ratio of the 592 and $614 \mathrm{~nm}$ emissions with increasing TR-BSA

Further analysis of the TRES datasets to obtain decay associated spectra was performed. It should be noted that by summing the individual decay associated spectra that the steady 
state spectra can be obtained (denoted sum) and this, as well as the decay associated spectra at each of the protein concentrations studied are shown in Figure 4. Considering the spectra without the addition of TR-BSA the sum of two exponential decays was required to globally fit the dataset. The results also help explain those of the TRES showing that the principle emission band is in fact split (emission at $614 \mathrm{~nm}$, lifetime $206 \mu \mathrm{s}$, and $616 \mathrm{~nm}$, lifetime $317 \mu \mathrm{s}$ ). The other band emissions for both decay associated spectra appear coincident. It should be kept in mind that the Eu-POM is in excess and there are several europium atoms present in the POM structure. Therefore upon addition of protein, at a lower concentration, a small proportion of the $\mathrm{Eu}^{3+}$ emission reflects the shielding effect of the protein, which increases as more protein is added.
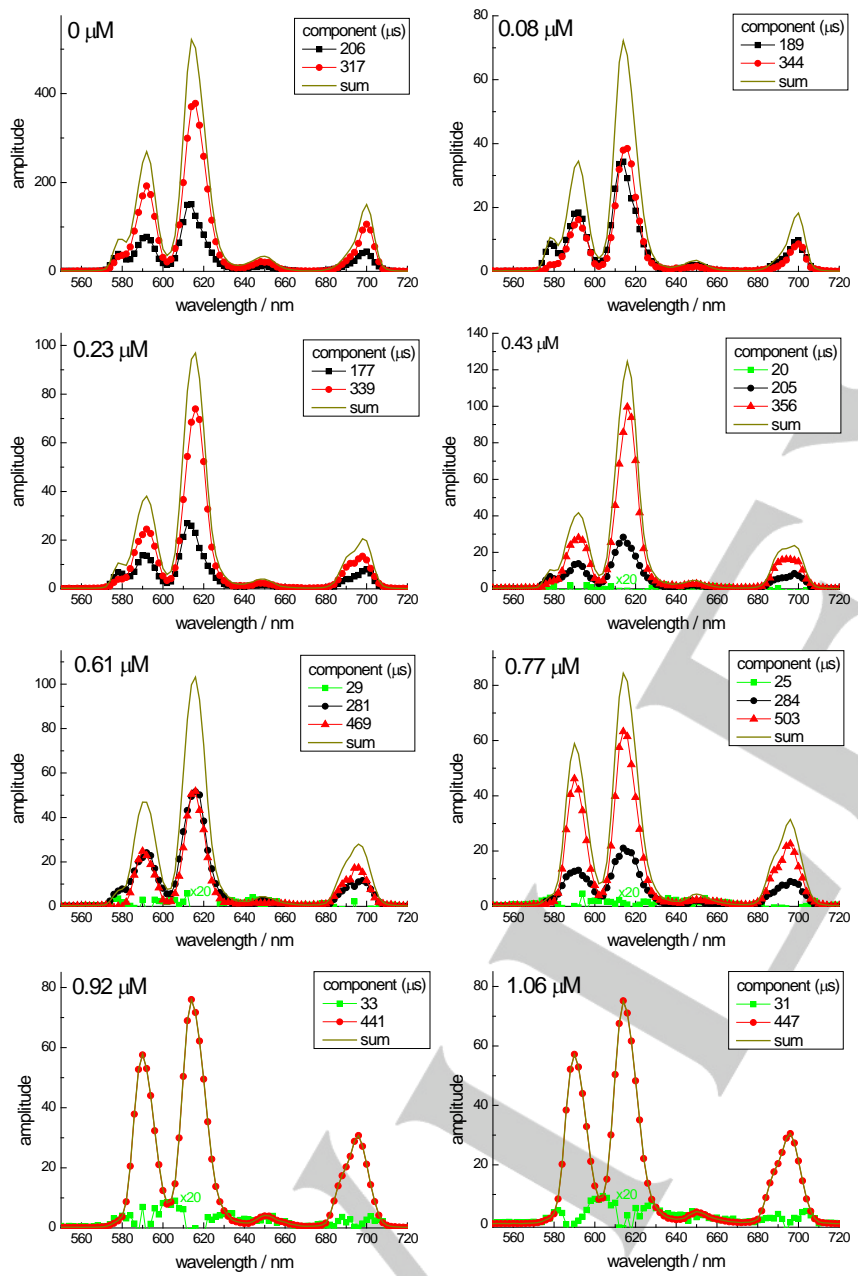

Figure 4. Decay associated spectra for the Eu-POM with different concentrations of TR- BSA. The sum (steady state) spectra are also shown. The lifetime error is $\sim 0.5 \mu \mathrm{s}$.

After the addition of $0.43 \mu \mathrm{M}$ of protein an extra, shorter-lived, decay component was required to fit the global dataset, although small in amplitude. For the final two protein concentrations studied again just the sum of two exponential decay components is required, with an increased presence of an emission close to $600 \mathrm{~nm}$, where Texas Red emits and a longer-lived decay accounting for the characteristic europium emission. Although the spectral contribution of the shortest-lived component is not that large, considering the sensitised emission lifetime of $\sim 31 \mu \mathrm{s}$, and the longer-lived decay, would imply that the energy transfer efficiency just a little less than that obtained for the Tb-POM and FITC-BSA system, but still in excess of $90 \%$. Using a value of 44 $\AA$ for $R_{0}{ }^{[39]}$ this returns a donor-acceptor distance of $28 \AA$, which is very close to that which we calculated for the Tb-POM and FITC-BSA system. It is also in keeping with another POMHSA. ${ }^{[2]}$ This is unsurprising considering the similarity in the structure of our POMs and is indicative that the protein binds in a comparable manner to both.

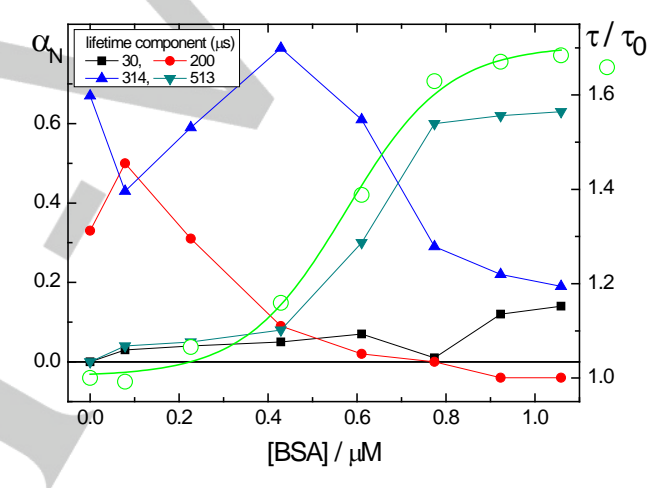

Figure 5. Combined global analysis of all datasets showing the change in the different pre-exponential factors $\left(\alpha_{N}\right)$ components with addition TR-BSA to Eu-POM. The relative change in average lifetime is also shown.

As there is a commonality in lifetimes between the datasets for Eu-POM with each protein addition, an extra global analysis was carried out by combining the sum decays from each dataset. In order to fit all the decays a model involving the sum of four exponentials was required, this increase is caused by the enlargement of the dataset by combining all the measurements. The outcome, showing the variation of the pre-exponential factors is given in Figure 5. Overall this figure shows an increase in the contribution of the $30 \mu \mathrm{s}$ component with protein addition, while the contribution of the $200 \mu$ s component decreases. A more interesting behaviour is seen with the contributions of the two longer-lived decay components. The longest (513 $\mu \mathrm{s})$ lifetime only really starts to contribute after the presence of 0.43 $\mu \mathrm{M}$ protein, a concentration at which the contribution of the 314 $\mu$ s decay peaks before decreasing. This is the same protein concentration as that noted in Figure $3 b$ for the increase in the $592 \mathrm{~nm}$ emission peak and could indicate that the longer component is associated with this emission. As the lifetime of the $\mathrm{Eu}^{3+}$ is not decreasing as would be expected, if a quenching mechanism was dominant, coupled by a spectrum consistent with sensitised Texas Red emission it is clear that more than one process is at work. In fact an increase in the lifetime of $\mathrm{Eu}^{3+}$ has been observed upon interaction with human serum 
albumin. ${ }^{[41]}$ Therefore, we suggest, that the dominant effect derives from the shielding influence of the protein causing an increase in the quantum yield and lifetime, with a smaller, opposite, influence on the $\mathrm{Eu}^{3+}$ photophysics coming from the sensitisation of the protein label.

\section{Conclusions}

In this paper it is clear that time-resolved measurements of these POM-protein systems with semiconductor laser excitation and subsequent determination of decay associated spectra are well suited to study sensitised emission via LRET. Both the spectra of the donor and sensitised acceptor can clearly be obtained from global analysis and associating the temporal and spectral information. The lifetimes obtained showed an efficient $(>90 \%)$ energy transfer process, with the sensitised emission from the protein label discerned at micromolar protein concentrations. The use of TRES also enabled changes in the donor spectra to be simultaneously observed. Although the results with the Tb-POM appear quite straight forward, those with the Eu-POM are more complex with direct interaction with the protein influencing the $\mathrm{Eu}^{3+}$ emission. This behaviour should be kept in mind if future bioimaging / assay applications are to be realised using this class of molecule.

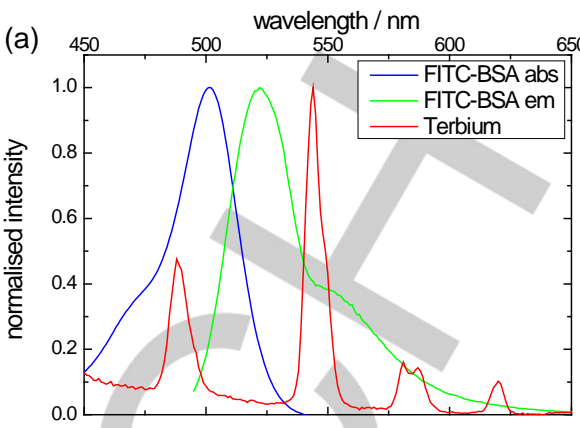

(b)

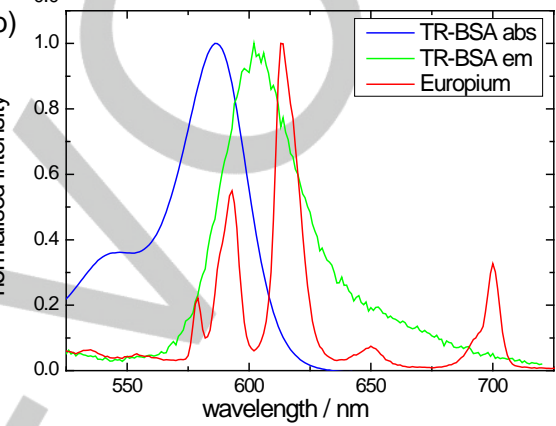

Figure 6. Normalised spectra for the POM emission and both the absorption and emission of the labels. (a) for the terbium study, (b) for the europium study.

\section{Experimental Section}

\section{Samples}

The iso-structured POMs (Tb-POM and Eu-PM), depicted in Scheme I, were prepared as described elsewhere ${ }^{[29]}$ and based on a caesium template. ${ }^{[42]}$. These were used at a concentration $\left(10^{-5} \mathrm{M}\right.$ to $\left.10^{-4} \mathrm{M}\right)$ to minimise POM-POM interactions. ${ }^{[29]}$ Bovine serum albumin (BSA) was obtained from Sigma-Aldrich and either labelled with FITC or Texas red (both Sigma-Aldrich) using standard procedures, i.e. coupling reaction carried out using carbonate buffer ( $\mathrm{pH}$ 9.3), followed purification via a size exclusion column (Sephadex G-25). The samples were checked using UV-vis spectroscopy and conditions (relative concentrations of protein and label) adjusted so that the tag to protein ratio was $1: 2.5$ to avoid label-label interactions. ${ }^{[40]}$ FITC labelled BSA was chosen for the study with the Tb-POM because of the spectral overlap and a report for the Förster distance $\left(R_{0}-\right.$ distance at which energy transfer is $50 \%$ efficient) for terbium and fluorescein of $45 \AA^{\left[{ }^{[32]}\right.}$ The Texas red europium combination have a reported $R_{0}$ of $44 \AA^{[39]}$ and the pertinent (normalised) spectra for these combinations are given in Figure 6. It should be noted that the Förster distance is considerably larger $(\sim \times 10)$ than if the energy transfer direction from intrinsic tryptophan to the lanthanide was considered. ${ }^{[21]}$

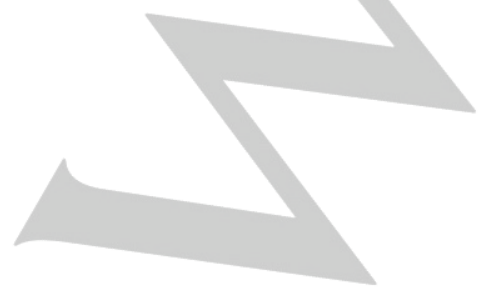

\section{Steady state measurements}

Steady state absorption measurements were performed using either a Shimadzu UV-1800 or a Perkin Elmer Lambda 2. The (uncorrected) fluorescence spectra were recorded using either HORIBA Scientific DeltaFlex or a FluoroMax 3.

\section{Time-resolved measurements}

Time-resolved measurements were performed on a HORIBA Scientific DeltaFlex equipped with DeltaDiode laser excitation sources. These were operated in "burst mode" with the $100 \mathrm{MHz}$ excitation pulse chain automatically gated using the DataStation software. For the terbium measurements a DD-375L (emission $378 \mathrm{~nm}$ ) was used and a DD-395L (emission $392 \mathrm{~nm}$ ) was employed for the europium measurements. Timeresolved emission spectra (TRES) were made by recording the timeresolved decay at $2 \mathrm{~nm}$ intervals for a fixed time period. This produced an intensity - wavelength - time, ie $3-D$, dataset. In the case of the terbium system 69 decays were obtained and 86 in the dataset for the europium system. "Time slices" were obtained using DataStation software and global analysis of the TRES data was performed, fitting to a sum of exponentials, using DAS6 software. This also allowed the sum decay of each TRES dataset to be determined by summing all of the individual wavelength dependent decays, thus reflecting the information of the entire wavelength range. This also enabled a global analysis of these sum decays to be performed. Decays were fitted as a sum of exponential components of the form;

$$
/(t)=\sum_{i=1}^{n} \alpha_{i} \exp \left(-t / \tau_{i}\right)
$$


With the contribution of each luminescent component represented by the normalised pre-exponential factor $\left(\alpha_{N i}\right)$, ie;

$$
\alpha_{N i}=\alpha_{i} / \sum_{i=1}^{n} \alpha_{i}
$$

This can also be expressed as a fractional ( $f$ ) to compare with the steady state emission, ie pre-exponential weighted by lifetime)

$$
f_{i}=\alpha_{i} \tau_{i} / \sum_{i=1}^{n} \alpha_{i} \tau_{i}
$$

The average lifetime was calculated using

$$
\tau_{\text {ave }}=\sum_{i=1}^{n} \alpha_{i} \tau_{i}^{2} / \sum_{i=1}^{n} \alpha_{i} \tau_{i}
$$

Goodness of fit was assessed by evaluation of the reduced chi-squared value and weighted residuals. The outcomes of the global analysis of the TRES data were then treated to produce decay associated spectra by plotting (using Origin software) the pre-exponential components, weighted by their lifetime, against wavelength.

Making use of the lifetimes obtained it is possible to calculate the efficiency $(E)$ of the energy transfer process using (5), where $\tau_{a d}$ in this case is the sensitised lifetime of the acceptor ${ }^{[32]}$ via LRET from the POM in the presence of labelled BSA and $\tau_{d}$ is the POM lifetime without addition of BSA

$$
E=1-\left(\tau_{a d} / \tau_{d}\right)
$$

From this the separation (R) of the donor and acceptor can be calculated, where $R_{0}$ is the Förster distance,

$$
R=R_{0}[(1 / E)-1]^{1 / 6}
$$

Keywords: Europium • LRET • Protein • Terbium • Timeresolved luminescence

[1] K. Binnemans, Chem. Rev., 2009, 109, 4283-4374.

[2] S. Omwoma, C.T. Gore, Y. Ji, C. Hu and Y.-F. Song, Coord. Chem. Rev., 2015, 286, 17-29.

[3] D. Menon, R.T. Thomas, S. Narayann, S. Maya, R. Jayakumar, F. Hussain, V.-K. Lakshmanan and S.V. Nair, Carbohydr. Polym., 2011 84, 887-893.

[4] H. Yanagie, A. Ogata, S. Mitsui, T. Hisa, T. Yamase and M. Eriguchi, Biomed. Pharmacother., 2006, 60, 349-352.

[5] J.G. Safar, H. Wille, M.D. Geschwind, C. Deering, D. Latawiec, A. Serban, D.J. King, G. Legname, K.H. Weisgraber, R.W. Mahley, B.L. Miller, S.J. DeArmond and S.B. Prusiner, Proc. Natl. Acad. Sci., 2006, 103, 11312-11317.

[6] D.A. Judd, J.H. Nettles, N. Nevins, J.P. Snyder, D.C. Liotta, J. Tang, J. Ermolieff, R.F. Schinazi and C.L. Hill, J. Am. Chem. Soc., 2001, 123 886-897.

[7] P.-E. Car, M. Guttenberg, K.K. Baldridge, R. Alberto and G.R. Patzke, Green Chem., 2012, 14, 1680-1688.

[8] D.-Y. Do, J.-S. Qin, S.-L. Li, Z.-M. Su and Y.-Q. Lan, Chem. Soc. Rev. 2014, 43, 4615-4632.

[9] J.M. Sumliner, H. LV, J. Fielden, Y.V. Geletii and C.L. Hill, Eur. J. Inorg. Chem., 2014, 635-644
[10] J.-C.G. Bünzli and S.V. Eliseeva, in Lanthanide luminescence: photophysical, analytical and biological aspects, P. Hänninen and $\mathrm{H}$ Härmä (Eds), Springer-Verlag Berlin Heidelberg, 2010, 1-45.

[11] M.H.V. Werts, Sci. Prog , 2005, 88, 101-131.

[12] J.-C.G. Bünzli and C. Piguet, Chem. Soc. Rev., 2005, 34, 1048-1077.

[13] J. Vuojola and T. Soukka, Methods Appl. Fluoresc., 2014, 2, 012001.

[14] J.-C.G. Bünzli, Chem. Rev., 2010, 110, 2729-2755.

[15] H. Dong, L.-D. Sun and C.-H. Yan, Nanoscale, 2013, 5, 5703-5714.

[16] J.-C.G. Bünzli, S. Comby, A.-S. Chauvin abd C.D.B. Vandevyver, J. Rare Earths, 2007, 25, 257-274.

[17] N. Sergent, J.A. Levitt, M. Green, K. Suhling, Opt. Express, 2010, 18 25292-25298.

[18] M.C. Heffern, L.M. Matosziuk and T.J. Mead, Chem. Rev., 2014, 114, 4496-4539.

[19] J.P. Leonard and T. Gunnlaugsson, J. Fluoresc., 2005, 15, 585-595.

[20] S.J. Butler, L. Lamarque, R. Pal and D. Parker, Chem. Sci., 2014, 5, 1750-1756.

[21] F.R Richardson, Chem. Rev., 1982, 82, 541-552.

[22] Q. Tang, S.-X. Liu, D.-D. Liang, F.-J. Ma, G.-J. Ren, F. Wei, Y. Yuang and C.-C. Li, J. Solid State Chem., 2012, 190, 85-91.

[23] G. Hungerford, M. Green and K. Suhling, Phys. Chem. Chem. Phys., 2007, 9, 6012-6015

[24] V. Goovaerts, K. Stroobants, G. Absillis and T.N. Parac-Vogt, Phys. Chem. Chem. Phys., 2013, 15, 18378-18387.

[25] G. Zhang, B. Keita, C.T. Craescu, S. Miron, P. de Oliveira and L. Nadjo J. Phys. Chem. B., 2007, 111, 11253-11259.

[26] G. Zhang, B. Keita, J.-C. Brochon, P. de Oliveira, L. Nadjo, C.T Craescu and S. Miron, J. Phys. Chem. B., 2007, 111, 1809-1814.

[27] L. Zheng, Y. Ma, G. Zhang, J. Yao, B.S. Bassil, U. Kortz, B. Keita, P. de Oliveira, L. Nadjo, C.T. Craescu and S. Miron, Eur. J. Inorg. Chem. 2009, 5189-5193.

[28] D. Ajloo, H. Behnam, A.A. Saboury, F. Mohamadi-Zonoz, B. Ranjbar A.A. Moosavi-Movahedi, Z. Hasani, K. Alizadeh, M. Gharanfoli and M. Amani, Bull. Korean Chem. Soc., 2007, 28, 730-736.

[29] G. Hungerford, F. Hussain, G.R. Patzke and M. Green, Phys. Chem. Chem. Phys., 2010, 12, 7266-7275.

[30] K.E. Sapsford, L. Berti and I.L. Medintz, Angew. Chem. Int. Ed., 2006 45, 4562-4588.

[31] P.R. Selvin, IEEE J. Select. Topics Quant. Electron., 1996, 2, 1077 1087

[32] P.R. Selvin, Annu. Rev. Biophys. Biomol. Struct., 2002, 31, 275-302.

[33] J. Chen, P.R. Selvin, J. Am. Chem. Soc., 2000, 122, 657-660.

[34] P.R. Selvin, T.M. Rana and J.E. Hearst, J. Am. Chem. Soc., 1994, 116 6029-6030.

[35] G. Mathis, Clin. Chem., 1993, 39, 1953-1959.

[36] S. Saraheimo, J. Hepojoki, V. Nurmi, A. Lahtinen, I. Hemmilä, A. Vaheri, O. Vapalahti and K. Hedman, PLoS One, 2013, 8, e62739.

[37] J.M. Zwier, H. Bazin, L. Lamarque and G. Mathis, Inorg. Chem., 2014 53, 1854-1866.

[38] K. Blomberg, P. Hurskainen and I. Hemmilä, Clinical Chem., 1999, 45 855-861.

[39] S. Stanimirov, I. Petkov, Spectrochim. Acta A, 2009, 72, 1127-1133.

[40] G. Hungerford, J. Benesch, J.F. Mano and R.L. Reis, Photochem. Photobiol. Sci., 2007, 6, 152-158.

[41] J. Hamblin, N. Abboyi and M.P. Lowe, Chem. Commun., 2005, 657-659.

[42] F. Hussain, B. Springler, F. Conrad, M. Spedrich, P. Kögerler, C Boskovic and G.R. Patzke, Dalton Trans., 2009, 4423-4425. 
Entry for the Table of Contents (Please choose one layout)

Layout 2:

\section{ARTICLE}

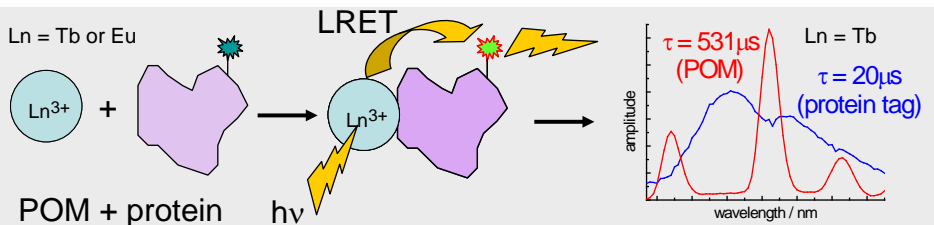

Lanthanide containing polyoxometalates were used to sensitise the emission of a fluorescent protein label via LRET upon binding. Global analysis of the timeresolved data enabled the spectra for both lanthanide and tag fluorophore to be discerned and the energy transfer efficiency calculated. However, using Eu in place of $\mathrm{Tb}$ in iso-structured POMs showed different spectral behaviour.
Dr A. Sheila Holmes-Smith, Jacob Crisp, Dr Firasat Hussain, Prof Dr Greta $R$ Patzke and Dr Graham Hungerford*

Page No. - Page No.

Use of lanthanide containing polyoxometalates to sensitise the emission of fluorescent labelled serum albumin 